ORIGINAL ARTICLE

\title{
Development of the specialty of emergency medicine in Israel: comparison with the UK and US models
}

\author{
P Halpern, Y Waisman, I P Steiner
}

Emerg Med J 2004;21:533-536. doi: 10.1136/emj.2003.004895

See end of article for authors' affiliations

.....................

Correspondence to:

Dr P Halpern, Department of Emergency Medicine, Tel Aviv Sourasky Medical Center, 6 Weizman Street, Tel Aviv 64239, Israel; dr_halperin@tasmc.health. gov.il

Accepted for publication 28 February 2003
Objectives: To describe the development of emergency medicine (EM) in Israel and review the specific problems faced by the discipline and describe the solutions that were found.

Methods: A comprehensive literature search was conducted for data on development of EM in the UK and in North America, and the personal knowledge of two of the authors (PH and YW) was used in preparing the article.

Results: There are differences in development of EM between Israel and the UK/US models. In Israel the specialty developed within the context of established high quality clinical practice and consequently it met resistance from the system, which did not wish to invest in what it felt might be marginal improvements in patient care. The economics of Israeli medicine also dictated that EM be made into a super-specialty rather than a primary specialty. Certified specialists from family medicine, paediatrics, internal medicine, general surgery, anaesthesia, and orthopaedic surgery can access training positions in EM. Currently there are seven active EM programmes of 2.5 years duration and 16 residents. The curriculum is flexible and a national certification examination is being developed.

Conclusions: Development of EM can and should take different paths according to the specific local needs and realities. There is no single ideal model suitable for all circumstances. The practice of clinical EM in Israel is comparable with that of any developed country and daily progress is being made in the academic areas of teaching and research. There are worldwide similarities in the process of developing EM as a distinct discipline.
E mergency medicine (EM) was officially recognised and accepted as a distinct discipline in the 1970s. The USA, Canada, Australia, and the UK pioneered the efforts to distinguish it among other branches of medicine, and EM has now evolved into an independent specialty. As of 2000, at least 18 countries have recognised this area of expertise and established training programmes, 13 countries have formal board certification, four have fellowships earmarked for EM, 28 have national organisations, and 27 are actively conducting research in the field. ${ }^{1}$ In Israel, official recognition of EM took place in 1999, and the academic aspects of the field have been slowly developing ever since.

This review compares the development and recognition of EM in a leading European and North American model with EM in Israel. The article will delineate the rationale for the special choices that went into creating the Israeli model compared with the options used in the other two long established prototypes.

\section{DEVELOPMENT AND CURRENT STATUS OF EM The UK}

In the UK, the Casualty Surgeons Association (CSA) later renamed the British Association for Accident and Emergency Medicine (BAEM) was created in 1967. In 1972 the Department of Health appointed the first 30 consultants for the specialty and organised the training and accreditation infrastructure. ${ }^{2}$ The national specialist accrediting body in the UK is currently the Specialist Training Authority (STA) but during the next year will be the Postgraduate Medical Education and Training Board (PMETB) (table 1). The first specialty examination was established in 1983. A professorial chair in accident and emergency (A\&E) was created in 1990, and today there are four in the country; these represent the highest faculty academic level in the UK system.
The course of postgraduate training for A\&E in the UK starts with a one year introductory training programme as house officers, followed by two years of general professional training as a senior house officer. A certification of higher qualification must be obtained in one of the following disciplines: surgery, internal medicine, anaesthesia, or A\&E to have access to the specialist registrar training spots in A\&E. Competition for these positions is robust. After a minimum five year training period, the specialist registrar can sit the examinations in A\&E. The Fellowship of the Faculty of Accident and Emergency (FFAEM) examination is administered on behalf of the Faculty of A\&E Medicine by the Intercollegiate Specialty Board (ISB). The examination is only a part of the assessment required before a doctor can be recommended to the STA as having completed specialist training and be recognised as a consultant in the UK.

Training in EM takes place in designated hospitals and junior level learners move around from one geographical area to another. Specialist registrar work in at least two hospitals and participate in the clinical duties of A\&E. Formal teaching for junior learners takes place weekly at scheduled times. Weekend training courses for senior house officers exist, and there are many other educational opportunities, such as life support courses and examination preparation.

Subspecialty areas of interest had been developed in critical care, paediatrics, sports medicine, and internal medicine departments. Formal fellowships exist only in the domain of research. ${ }^{23}$

Continuing medical education (CME) and faculty development courses that are A\&E specific are not at the same level presently as those in the US in terms of numbers and

Abbreviations: $E D$, emergency department; $E M$, emergency medicine; $\mathrm{TC}$, trauma centre; $C M E$, continuing medical education; $\mathrm{EP}$, emergency physician 
Table 1 UK, US and Israeli residency training programmes in emergency medicine: current status

\begin{tabular}{llll}
\hline & UK & US & Israel \\
\hline National specialist accrediting body & STA/PMTEB & ABEM & IAM \\
Certification & Specialty & Specialty & Super-specialty \\
Examination & National & National & In development \\
Training programmes* & 30 & 124 & 7 \\
Annual graduates & 319 & 1136 & $16 \dagger$ \\
Fellowships (types) & 1 & 21 & 0 \\
Curriculum/objectives & Mixed & Standardised & Flexible \\
Administrative authority & Programme director & Programme director & Programme director \\
\hline \multirow{2}{*}{ Active programmes. } & & &
\end{tabular}

content. Active efforts are currently being undertaken to further develop this area. The Emergency Medicine Journal provides a uniquely British opportunity for academic publications relevant to the practice of EM (http://www.emjonline. com).

\section{The US}

In the US, The first formal EM residency training programmes started at the University of Cincinnati and the Medical College of Pennsylvania in the early 1970s, and soon evolved into formal three year duration programmes. "The Guidelines for Residency Training in Emergency Medicine" developed by the Royal College of Physicians and Surgeons of Canada in 1973, served as a resource for early US programme development. ${ }^{5}$ The American Board of Emergency Medicine (ABEM) was established with a mandate to develop criteria for eligibility and certification in EM. In 1987, when there were 67 residency programmes ABEM specified that the minimum length of approved training programmes would be three years, and that an alternative programme length of four years was also approved. ${ }^{6}{ }^{7}$ By 1991, fellowships in medical toxicology and paediatric EM evolved and currently there are 21 along with subspecialties in paediatric EM, medical toxicology, and sports medicine ${ }^{89}$ (http://www.abem.org) (table 1). Various master level programmes are also available in areas of clinical epidemiology, education, public health, and others.

The EM core content education has been standardised and was well described..$^{10}$ Clinical rotations for residents are complemented by a variety of other teaching activities, for example, rounds, academic half days, journal clubs, etc. The teaching staff is comprised of board certified emergency physicians (EP). Board certification in EM can be obtained for allopathic and osteopathic physicians through ABEM, and for osteopathic physicians through the American Board of Osteopathic Emergency Medicine (ABOEM). The American Board of Medical Specialties recognises these two EM boards as the only approved organisations for EM specialist certification. $^{11}$

Over the years, many CME and faculty development courses have been developed for practising EPs as well as faculty members. Research and academic activities are published in 17 different adult or paediatric EM publications in the US alone. ${ }^{12}$

\section{Israel}

In Israel, all 27 general hospitals are mandated to provide EM care. ${ }^{13}$ The population of Israel is 6.5 million, and there are 2.3 million annual emergency department (ED) visits. In the early 1990s, EDs were small in size, under-equipped, chronically understaffed, and comprehensive, 24 hour seven days a week EM care did not exist. EDs were staffed with physicians with diverse training backgrounds, who could not find employment elsewhere. On-call residents from medical and surgical departments, often without direct supervision, were responsible for all patient care related decision making after hours and on weekends. The ED was compartmentalised, and specialties such as internal medicine, paediatrics, obstetrics and gynaecology, general and orthopaedic surgery, were providing primary patient care in their specific domain.

The Gulf war in 1991 exposed many inadequacies of EDs in terms of accommodating massive numbers of casualties and this triggered major changes in the ensuing years. After 1993, a national trauma system was created; six institutions were designated as level 1 trauma centres (TCs) and 12 others as level 2 TCs. The trauma units in these EDs are staffed continuously by qualified trauma surgeons. After 1994, EDs were redesigned, modernised, and most of their directors were replaced with career EPs who had Israeli board certification in internal medicine, anaesthesiology and intensive care, paediatrics, or surgery.

The Israeli Association for Emergency Medicine (IAEM) was created in 1992. In 1994 IAEM formed a committee with the Israeli Medical Association (IMA) the national organisation responsible for the recognition of specialties in Israel and with the Scientific Committee (SC) of the IMA with the mandate to look at the various specialty options. In 1999, EM was recognised as a "super-specialty". To become an EM specialist in Israel, a board certified physician in internal medicine, general surgery, anaesthesiology, paediatrics, orthopaedic surgery, or family medicine must undergo another 2.5 years of training in EM. Thus, the EM resident is a specialist being "retrained" in the horizontal discipline of EM.

Between 1999 and 2002, 63 EPs from the six accredited primary specialties were granted specialist status through a "grandfather clause". A national examination process for certification in EM for residents has been developed and implemented. The IAEM has developed formal residency programme accreditation guidelines that comply with SC requirements. A committee of peers approved each prospective hospital based EM programme. Full official approval required that, over the 2.5 years training period, all training objectives be met in that institution. Partial approval was granted to those institutions that had to send residents to other centres for training in major trauma or other domains. To date, nine EDs have been fully and seven partially approved. Currently, seven of the EDs have residency programmes with one to four residents in each (table 1). Fellowships or areas of subspecialties in EM do not exist in Israel.

The objectives and content of the curriculum focus upon exposure to areas of EM training not covered during their primary specialty training. Active participation in departmental and extra-departmental educational activities is mandatory. The residents are encouraged to participate in other academic and educational endeavours of the IAEM, including the internationally attended annual meeting.

Programme directors are board certified in EM, and instruction is currently provided by full time EPs with or 
without EM certification. On off-service rotations, the residents are trained by specialists in those domains. Residents in EM will gradually take over from the attending physicians the clinical education in the ED of medical students and residents from other disciplines.

CME in EM has been provided annually to 35-40 physicians by the Sackler Faculty of Medicine at the Tel Aviv University. Faculty development was funded by the Dreznick-Gottlieb families and four EPs were sent annually to US academic EDs for four to six week minifellowships.

The Israeli Journal of Trauma, Intensive Care and Emergency Medicine, created in 2001, is the official journal of the IAEM and it offers a forum for the dissemination of academic, clinical, and research initiatives for Israeli EPs thus providing a higher academic profile for the discipline.

\section{DISCUSSION}

In the process of developing EM, Israeli EPs had to deal with similar and dissimilar problems from those encountered by colleagues from other parts of the world. The security needs of the state of Israel dictate the priorities of funding allocations. Money for health care and education in Israel is provided exclusively by the national government. This is similar to the UK, whereas funding for patient care and education fall under a mix of private and governmental jurisdiction as in the US.

There are fundamental differences between the Israeli approach to EM training and that of the UK and US specialists (table 1). The SC has recognised EM as a superspecialty because it doubts that EM is able to produce through a straight post MD programme a clinically experienced and mature physician for the specific needs of Israel. Financial considerations also played a factor. Hospital based EPs have fixed hospital salaries and an exclusively ED based physician is non-competitive with incomes generated by specialists in private practice. To attract high calibre people EPs need to achieve economic parity by supplementing their income through private practice in their primary discipline. The list of primary specialties that can access EM training is specific to Israel and was developed as a compromise between IAEM and the representatives of the 54 existing specialties.

In the UK preliminary training in traditional disciplines is also required before accessing the EM specific track, but EM is still a primary specialty. The US model requires that specific training starts immediately after MD and EM is considered a primary specialty.

The objectives of EM residencies in Israel are less detailed or subject to formal national guidelines and the curriculum is flexible because the trainees are already specialists and they need to acquire knowledge and skills in other specific domains. The UK model has strict guidelines for the general training however it offers some flexibility in education for the A\&E registrar portion. This flexibility, much like in the Israeli model, is there because of the variety of training backgrounds of the registrars. The US on the other hand has formal national objectives, guidelines for training, and the curriculum is somewhat standardised.

The philosophy of national certification in the three countries is similar: each requires that prospective specialist candidates meet minimum standards.

Lastly, the emergence of national EM journals also shows agreement between the three models on the requirement to advance the academic discipline. The difficulties encountered by Israeli EM in establishing its academic credibility is probably more acute because of the lack of time to develop a critical number of knowledgeable clinicians, respected educators, and researchers and the journal should help. In
Israel for example there are only a few people with junior and mid-level academic appointments. Protected academic time and funding is unavailable. While the situation in the UK is not well recorded, the presence of four professorial chairs and the ever increasing EM specific publications by British authors would suggest that A\&E in the UK is progressing well. The situation in the US is enviable: $36 \%$ of the EM faculty is on an academic tenured track, and academic workloads and protected time are better defined..$^{14-17}$ Academic productivity of EPs is high as judged by the quality and volume of publications.

\section{CONCLUSION}

National differences in culture, economy, medical economics, medical tradition, and geo-political reality may necessitate the implementation of different solutions to the same problems and EM development in each jurisdiction across the globe will reflect this reality. Those contemplating developing EM as a distinct discipline should note that in terms of evolution there are at least two important similarities found not only in the three models described but also in other world leaders. Firstly, a national association was created in each setting with the goals to spearhead the development of EM and to play a leading part in promoting the discipline. Secondly, the political victory in the quest for recognition of EM as a distinct discipline was won in all instances in the arena dealing with advocacy on behalf of quality patient care. Once this battle was over, the other steps, such as the formalisation of the accreditation process, the development of training programmes, and the creation of a national certification examination need to follow expeditiously and efficiently, to preserve the momentum.

\section{ACKNOWLEDGEMENTS}

Ms Esther Eshkol for editorial assistance. For support in kind: Department of Emergency Medicine, Tel Aviv Medical Center, Tel Aviv and the Sackler Faculty of Medicine Tel Aviv University, Tel Aviv, Israel; Unit of Emergency Medicine, Shneider's Children Hospital, Petach Tiqva, Sackler Faculty of Medicine Tel Aviv University, Tel Aviv, Israel; Israeli Association for Emergency Medicine, Tel Aviv, Israel; Department of Family Medicine and Division of Emergency Medicine University of Alberta, Edmonton, Canada.

\section{CONTRIBUTORS}

Dr Halpern: author, joint idea for publication, manuscript preparation, and review. Dr Waisman: participated in the review, discussion, and preparation of the manuscript. Dr Steiner: senior author, joint idea for publication, manuscript preparation, and review.

\section{Authors' affiliations}

P Halpern, Department of Emergency Medicine, Tel Aviv Sourasky Medical Center, Israel

Y Waisman, Unit of Emergency Medicine, Schneider National Children's Hospital, Petach Tikva, Israel

I P Steiner, Department of Family Medicine and Division of Emergency Medicine, Faculty of Medicine and Dentistry, University of Alberta, Edmonton, Alberta, Canada

The Tel Aviv Sourasky Medical Center and Schneider National Children's Hospital are both affiliated with the Sackler Faculty of Medicine, Tel Aviv University, Tel Aviv, Isreal.

\section{REFERENCES}

1 Arnold L, Dickinson G, Tsai MC, et al. A survey of emergency medicine in 36 countries. Can J Emerg Med 2001;3:109-18.

2 McHugh DF, Driscoll PA. Accident and emergency medicine in the United Kingdom. Ann Emerg Med 1999;33:702-9.

3 Davis $\mathbf{F}$. The future of paediatric accident and emergency medicine. J R Soc Med 2000;93:484-6.

4 Sutnick Al, Wagner DK. Emergency medicine as an academic discipline. J Am Med Assoc 1977;238:147-8. 
5 Walker DMC. Emergency medicine in perspective. Can J Emerg Med 1982;127:127-9.

6 Sloan EP, Strange GR, Jaynes HA. United States emergency medicine residency length in 1986-87 and 1987-88. Ann Emerg Med 1987:16:862-6.

7 American Medical Association Accreditation Council for Graduate Medical Education (ACGME). ACGME requirements for certification of emergency residency programs. Graduate medical education directory 1998-99. Chicago: American Medical Association, 1999:57-62.

8 Tenenbein $M$. The combined pediatric emergency medicine-clinical toxicology fellowship. Pediatr Emerg Care 1991;7:38-9.

9 Hoffman GL, Bock BF, Gallagher EJ, et al. Report of the task force on residency training information (2001-2002), American Board of Emergency Medicine. Ann Emerg Med 2002;39:510-27.

10 Hockberger RS, Binder LS, Graber MA, et al. The model of the clinical practice of emergency medicine. Ann Emerg Med 2001;37:745-70.
11 American Board of Medical Specialties Research and Education Foundation Annual reference handbook. Evanston, IL: American Board of Medical Specialties Research and Education Foundation, 1996:128.

12 Medibioword. htpp://www.medbioword.com/med/journal/medjournal.htm.

13 Waisman Y, Amir L, Or J. Emergency medicine in Israel: state of the art. Ann Emerg Med 1995;26:640-2.

14 Sanders AB, Spaite DW, Smith R, et al. Allocation of time in three academic specialties. J Emerg Med 1988;6:435-7.

15 Meislin HW, Spaite DW, Valenzuela TD. Meeting the goals of academia: characteristics of emergency medicine faculty academic work styles. Ann Emerg Med 1992;21:298-302.

16 Wright SW, Slovis CM. Tenure track in emergency medicine. Ann Emerg Med 1997:30:622-5

17 Bernstein $\mathbf{E}$, James T, Bernstein J. Sabbatical programs and the status of academic emergency medicine: a survey. Acad Emerg Med 1999;6:932-8.

\section{Clinical Evidence-Call for contributors}

Clinical Evidence is a regularly updated evidence based journal available worldwide both as a paper version and on the internet. Clinical Evidence needs to recruit a number of new contributors. Contributors are health care professionals or epidemiologists with experience in evidence based medicine and the ability to write in a concise and structured way.

\section{Currently, we are interested in finding contributors with an interest in} the following clinical areas:

Altitude sickness; Autism; Basal cell carcinoma; Breast feeding; Carbon monoxide poisoning; Cervical cancer; Cystic fibrosis; Ectopic pregnancy; Grief/bereavement; Halitosis; Hodgkins disease; Infectious mononucleosis (glandular fever); Kidney stones; Malignant melanoma (metastatic); Mesothelioma; Myeloma; Ovarian cyst; Pancreatitis (acute); Pancreatitis (chronic); Polymyalgia rheumatica; Post-partum haemorrhage; Pulmonary embolism; Recurrent miscarriage; Repetitive strain injury; Scoliosis; Seasonal affective disorder; Squint; Systemic lupus erythematosus; Testicular cancer; Varicocele; Viral meningitis; Vitiligo However, we are always looking for others, so do not let this list discourage you.

\section{Being a contributor involves:}

- Appraising the results of literature searches (performed by our Information Specialists) to identify high quality evidence for inclusion in the journal.

- Writing to a highly structured template (about 2000-3000 words), using evidence from selected studies, within 6-8 weeks of receiving the literature search results.

- Working with Clinical Evidence Editors to ensure that the text meets rigorous epidemiological and style standards.

- Updating the text every eight months to incorporate new evidence.

- Expanding the topic to include new questions once every 12-18 months.

If you would like to become a contributor for Clinical Evidence or require more information about what this involves please send your contact details and a copy of your CV, clearly stating the clinical area you are interested in, to Claire Folkes (cfolkes@bmigroup.com).

\section{Call for peer reviewers}

Clinical Evidence also needs to recruit a number of new peer reviewers specifically with an interest in the clinical areas stated above, and also others related to general practice. Peer reviewers are health care professionals or epidemiologists with experience in evidence based medicine. As a peer reviewer you would be asked for your views on the clinical relevance, validity, and accessibility of specific topics within the journal, and their usefulness to the intended audience (international generalists and health care professionals, possibly with limited statistical knowledge). Topics are usually 2000-3000 words in length and we would ask you to review between 2-5 topics per year. The peer review process takes place throughout the year, and our turnaround time for each review is ideally 10-14 days.

If you are interested in becoming a peer reviewer for Clinical Evidence, please complete the peer review questionnaire at www.clinicalevidence.com or contact Claire Folkes(cfolkes@bmigroup.com). 